\title{
Correlation and Predictive Value of the FDG uptake within Primary Mass in Non-small Cell Lung Carcinoma and Incidence of Distal Metastases
}

\author{
Gokulakrishnan PR ${ }^{1}$, Arunan Murali², Bhasker Raj ${ }^{3}$, Venkata Sai ${ }^{4}$ \\ ${ }^{1}$ Associate Professor, Department of Radiology, ${ }^{2}$ Associate Professor, Department of Radiology, ${ }^{3}$ Professor, Department of \\ Radiology, ${ }^{4}$ Professor and HOD, Department of Radiology, Sri Ramchandra Medical College, Porur, Chennai - 600116, India
}

Corresponding author: Dr. Arunan, Department of Radiology, Sri Ramachandra Medical College, Porur, Chennai - 600116, India

DOI: $10.21276 / \mathrm{ijcmsr} .2018 .3 .3 .24$

How to cite this article: Gokulakrishnan PR, Arunan Murali, Bhasker Raj, Venkata Sai. Correlation and predictive value of the FDG uptake within primary mass in non-small cell lung carcinoma and incidence of distal metastases. International Journal of Contemporary Medicine Surgery and Radiology. 2018;3(3):C108-C111.

\section{A B S T R A C T}

Introduction: Identification of tumour anatomic and functional features may allow us a better understanding of cancer dissemination. Here, we investigated how 18-Fluorine -Fluoro-2-Deoxyglucose [FDG] uptake influences the incidence of distal metastases.

Material and Methods: We retrospectively evaluated 18-Fluorine -Fluoro-2-Deoxyglucose Positron emission tomography integrated with computed tomography [FDG-PET/CT] of 35 patients with Non-Small cell carcinoma [NSCLC], who had come for pre-treatment staging of the disease.

Results: The mean FDG uptake of the tumour was maximum Standardized Uptake value [SUV max] of 10.73. 21 of the 35 patients had metastases. Metastases to the bone was the most frequent. The Pearson correlation between the FDG uptake and incidence of metastases was 0.013 , suggesting negligent linear correlation between the two.

Conclusion: Non-small cell lung carcinoma tumour have a favoured spread to the bones. FDG uptake cannot be taken as an independent parameter to predict the incidence of metastases in NSCLC

Keywords: Non-Small Cell Lung Carcinoma, FDG-PET/CT, SUV Max, Metastases.

\section{INTRODUCTION}

Lung carcinoma is the second most common cancer in both men and women. In men, prostate carcinoma is most common, while in women, breast carcinoma is the most common. Of all cancers, lung carcinoma accounts for about 14 percent of all new cancers and 19 percent of cancer related deaths. ${ }^{1}$ Lung carcinoma is divided into Non-Small cell carcinomas and Small cell carcinomas. The use of these terms is however being challenged. ${ }^{2}$ Squamous cell carcinoma is commonest histological subtype. ${ }^{3}$ Presence and site of metastases is important to the clinical course and outcome of the patients.

Metastases to distal organs occurs by cancer cell migration and subsequent survival and proliferation. Distribution of metastatic spread is a not matter of chance but rather due to biological compatibility between the migrating cancer cells and receiving organ, according to the "seed" and "soil" hypothesis. ${ }^{4}$ Distal metastases is present in 18-36 percent of the cases at the time of diagnosis. ${ }^{5}$ Adrenal glands, bones, liver and brain are the common sites of metastases.

FDG-PET/CT is widely used for the evaluation of malignant tumours ${ }^{6}$, where FDG uptake serves as a marker of increased glycolytic activity. FDG-PET/CT provides quantitative and semiquantitative measurement of glycolytic activity over the tumour volume in a simple, non-invasive and reproducible manner, unlike histopathological tests. Maximum Standardized Uptake value [SUV $\max$ ] is a semiquantitative method of measuring the tumour glucose metabolism and reflects the tumour aggressiveness.

In this study, we thus investigated whether there exist a correlation between the FDG uptake in primary tumour and the incidence of distal metastases and also if the FDG uptake can be used an independent predictor of distal metastases.

\section{MATERIAL AND METHODS}

We retrospectively analysed the FDG-PET/CT of 35 patients with histopathologically proven patients Non-Small Cell Lung Carcinoma who came had come to our institution [Sri Ramachandra Medical Centre, Chennai, India] for pre-treatment staging. Patients who had prior neoadjuvant chemotherapy or radiotherapy were excluded from our study.

\section{FDG-PET/CT imaging}

Patients were asked to fast at least $6 \mathrm{~h}$ before the FDGPET-CT scan. All patients had a glucose level below 180 $\mathrm{mg} / \mathrm{dl}$ and were injected intravenously with $0.22 \mathrm{mCi}(8.14$ $\mathrm{MBq}) / \mathrm{kg}$ (5-8 mCi/260-320 MBq) FDG. At 60-90 min 
after the injection, data were acquired from the vertex to the upper thigh. The first CT scan was performed using $120 \mathrm{kV}$, $130 \mathrm{~mA}$, and a 3-mm section thickness. Immediately after CT, a PET scan (Siemens Biograph Horizon; Siemens Medical Solutions, Inc., Malvern, PA, USA) was performed for about $7 \mathrm{mins}$, with seven to eight bed positions and $1 \mathrm{~min} /$ position. PET images were reconstructed iteratively with CT data for attenuation correction, using an inline integrated Siemens Esoft Workstation system.

\section{Image Analysis}

Images were then transferred to Workstation (Siemens Syngovia workstation, Siemens Medical Solutions, Inc., Malvern, PA, USA). Computerized tomography integrated positron emission tomography fusion images in transaxial, sagittal, and coronal planes were evaluated. Maximum standardised uptake values [SUV max] were based on the hottest pixel within the region of interest [ROI] drawn around the primary tumour on an attenuation-correction/ PET-CT fused image. Presence or Absence of distal metastases was recorded as binarily.

\section{STATISTICAL ANALYSIS}

Data was exported on to a Microsoft excel sheet. The mean of the measurement data was expressed as mean \pm standard deviation [mean $\pm \mathrm{SD}]$. Analysis of the data was done using Pearson's correlation coefficient. Statistical analysis was done using SPSS 17.0 [Chicago, Illinois, USA].

\section{RESULTS}

Of the 35 patients included in the study, 25 were male and 10 were female. Age varied from 35 to 77 years. The lowest
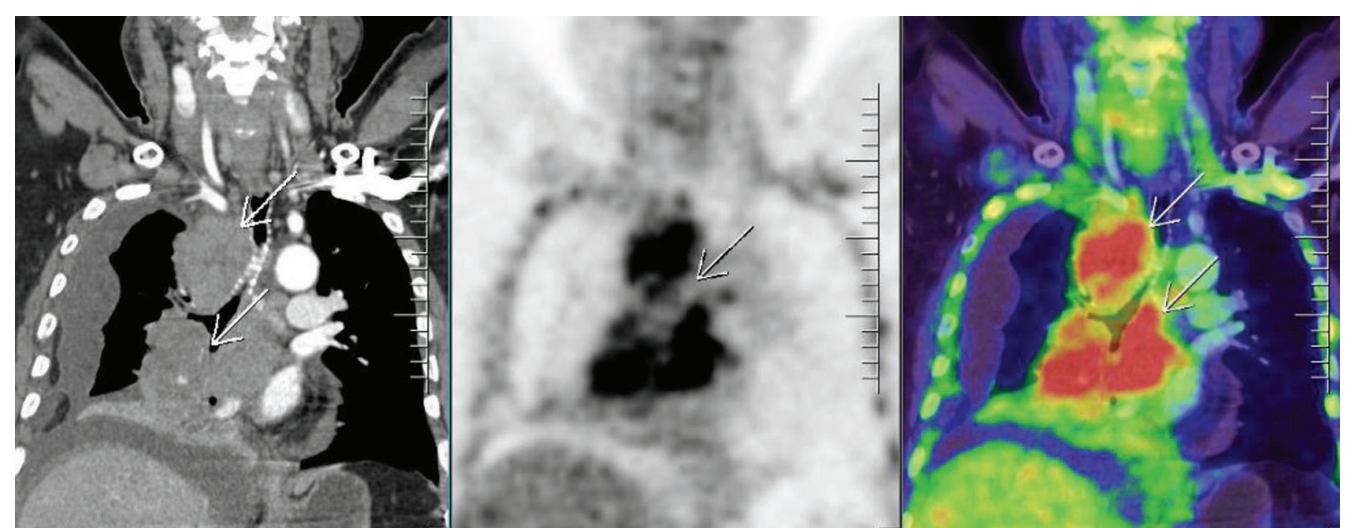

Figure-1: Coronal CT, PET and PET/CT fusion images showing FDG Avid masses in the right Lung.
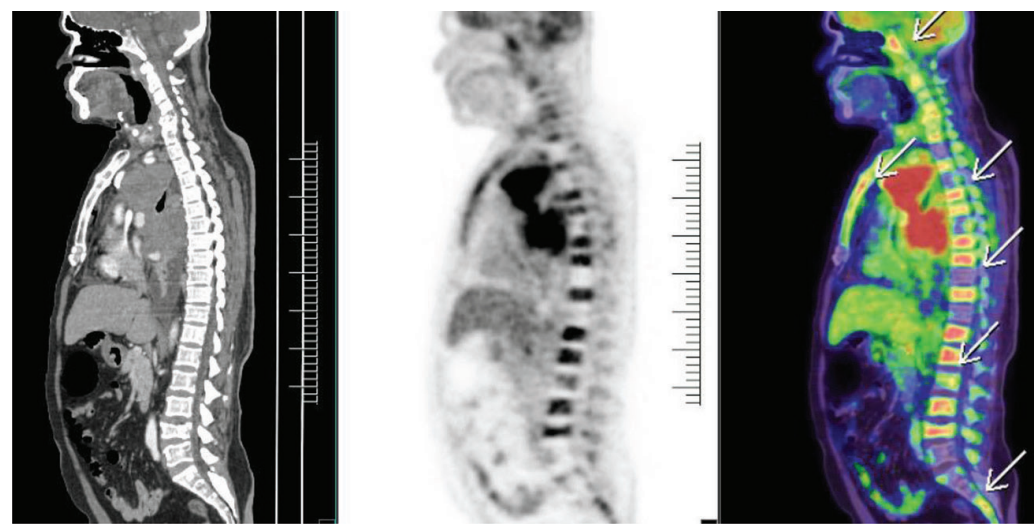

Figure-2: Sagittal CT, PET and PET/CT fusion images showing FDG avid metastases in multiple vertebra.
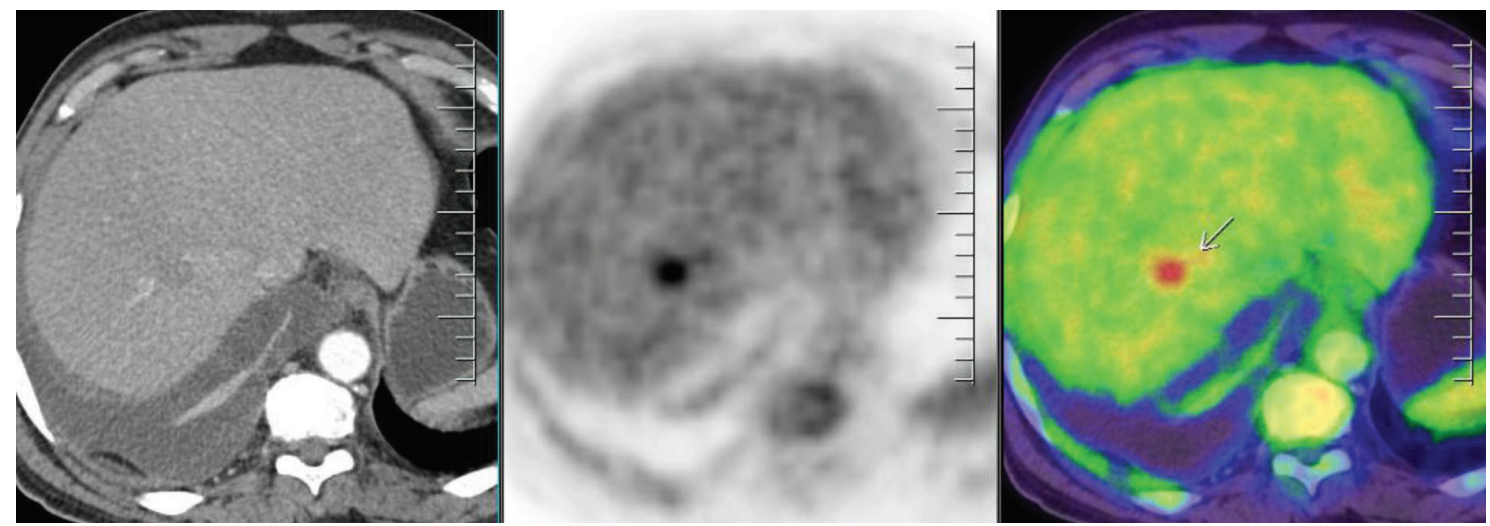

Figure-3: Axial CT, PET and PET/CT fusion images showing a FDG Avid Metastases in segment VIII of liver. 


\begin{tabular}{|c|c|}
\hline SUV max & Metastases $(\mathrm{Y} / \mathrm{N})$ \\
\hline 1.07 & $\mathrm{~N}$ \\
\hline 4.76 & $\mathrm{~N}$ \\
\hline 7.57 & $\mathrm{~N}$ \\
\hline 8.54 & $\mathrm{~N}$ \\
\hline 8.56 & $\mathrm{~N}$ \\
\hline 8.83 & $\mathrm{~N}$ \\
\hline 9.05 & $\mathrm{~N}$ \\
\hline 9.67 & $\mathrm{~N}$ \\
\hline 11.4 & $\mathrm{~N}$ \\
\hline 12.28 & $\mathrm{~N}$ \\
\hline 12.46 & $\mathrm{~N}$ \\
\hline 14.8 & $\mathrm{~N}$ \\
\hline 14.8 & $\mathrm{~N}$ \\
\hline 25.5 & $\mathrm{~N}$ \\
\hline 4.3 & $\mathrm{Y}$ \\
\hline 4.93 & $\mathrm{Y}$ \\
\hline 5.9 & $Y$ \\
\hline 6.19 & $Y$ \\
\hline 7.92 & $Y$ \\
\hline 8.29 & $Y$ \\
\hline 8.52 & $Y$ \\
\hline 8.53 & $Y$ \\
\hline 8.9 & $\mathrm{Y}$ \\
\hline 9.97 & $\mathrm{Y}$ \\
\hline 10.1 & $Y$ \\
\hline 10.67 & $Y$ \\
\hline 11 & $Y$ \\
\hline 11.1 & $\mathrm{Y}$ \\
\hline 13 & $Y$ \\
\hline 13.2 & $\mathrm{Y}$ \\
\hline 13.26 & $\mathrm{Y}$ \\
\hline 15 & $\mathrm{Y}$ \\
\hline 17.68 & $Y$ \\
\hline 18 & $\mathrm{Y}$ \\
\hline 20.14 & $\mathrm{Y}$ \\
\hline
\end{tabular}

SUVmax was 1.07 and the highest SUV max was 20.14. The Mean SUVmax was 10.73 with a standard deviation of 4.80 (Figure 1). 21 of the 35 patients had distal metastases, with the bones being the most common site (Figure 2, Figure 3). The data is summarized in Table 1.

The Pearson Correlation Coefficient was 0.013, suggestive of negligible correlation. ${ }^{7}$

\section{DISCUSSION}

In this study, we examined the common sites of metastases and also if the FDG uptake correlates with the incidence of distal metastases.

Results revealed that the bone was the most frequent site of distal metastases. Carr LL. et al. found that adrenal gland was the commonest site, found in approximately 33\% at autopsy. ${ }^{8}$ Radionuclide bone scan with $99 \mathrm{mTc}$-methylenediphosphonate was usually used for the detection of occult metastases, but, it had a high false-positive rate. ${ }^{9}$ FDG-PET/ CT has an accuracy of 98 percent in detecting bone metastases as compared to 87 percent with bone scintigraphy. ${ }^{10}$ Meta- analysis studies showed that the pooled sensitivity and specificity of FDG PET/CT for detecting distant metastasis from NSCLC were 0.87 [95 percent CI, 0.55-0.98] and 0.96 [95 percent CI, 0.93-0.98], respectively. ${ }^{11}$ FDG$\mathrm{PET} / \mathrm{CT}$ has a high sensitivity [97 percent] and specificity [86 percent] for metastatic adrenal disease in NSCLC. ${ }^{12}$ However, high glucose uptake by the gray matter and small size of the lesions restricts the diagnostic capability of FDG$\mathrm{PET} / \mathrm{CT}$ in the detection of brain metastases ${ }^{13}$, so MRI is the preferred modality of choice.

Our study also found no significant correlation between the FDG uptake in the primary tumour and in the incidence of metastases. Many studies have reported high FDG uptake with poorer prognosis ${ }^{14,15,16}$, however, others have found that it is not an independent predictor of overall survival. ${ }^{17,18}$ FDG uptake was not recommended for risk stratification in the 7th edition of the American Joint committee on cancer staging manual. ${ }^{20}$ In the National Comprehensive Cancer Network guidelines [version 3, 2014], it is not considered a prognostic biomarker. ${ }^{21}$ Study by Shou-Hui Zhu et al. inferred that higher FDG uptake by the primary tumour had a high extension and metastatic potential.21 Li et al. reported that FDG uptake of primary tumour was a potential indicator of metastases in T1 stage NSCLC. ${ }^{22}$

Limitation of our study was that it was retrospective study, which could have caused selection bias, and also our sample size.

\section{CONCLUSION}

Although FDG uptake by a primary tumour is an indicator of the tumour metabolic activity and aggressiveness, the same cannot be used as an predictive indicator of the incidence of distal metastases. The favourable context of the bone appears to allow seeding of the tumour cells regardless of their FDG activity. Further investigations are required to assess the precise role of FDG uptake as an independent predictor of metastases.

\section{REFERENCES}

1. Ferlay J, Soerjomataram I, Ervik M, Dikshit R, Eser S, Mathers C, et al. Lyon, France: International Agency for Research on Cancer; 2013. [accessed on January 21, 2014]. GLOBOCAN 2012 v1.0, Cancer Incidence and Mortality Worldwide: IARC Cancer Base No. 11.

2. Ettinger DS. National Comprehensive Cancer Network; 2012. [accessed on January 21, 2014]. NCCN Clinical Practice Guidelines in Oncology for Non Small Cell Lung Cancer, Ver 2.2012.

3. Lung cancer in India. Behera D, Balamugesh T. Indian J Chest Dis Allied Sci. 2004; 46(4):269-81.

4. The pathogenesis of cancer metastasis: the 'seed and soil' hypothesis revisited. Fidler IJ. Nat Rev Cancer. 2003; 3:453-8.

5. Quint LE. Staging non-small cell lung cancer. Cancer Imaging. 2007;7(3):148-59.

6. PET/CT imaging in cancer: current applications and future directions. Farwell MD, Pryma DA, Mankoff DA. Cancer. 2014; 120(22):3433-45.

7. Hinkle DE, Wiersma W, Jurs SG. Applied Statistics for the Behavioral Sciences. 5th ed.Boston: Houghton 
Mifflin; 2003.

8. Evaluation and treatment of patients with non-small cell lung cancer. Carr LL, Finigan JH, Kern JA. Med Clin North Am. 2011; 95(6):1041-54.

9. Positron emission tomography/computed tomography in lung cancer staging, prognosis, and assessment of therapeutic response. Truong MT, Viswanathan C, Erasmus JJ. J Thorac Imaging. 2011; 26(2):132-46.

10. Detection of bone metastases: assessment of integrated FDG PET/CT imaging.Taira AV, Herfkens RJ, Gambhir SS, Quon A. Radiology. 2007 Apr; 243(1):204-11.

11. Li J, Xu W, Kong F, Sun X, Zuo X. Meta-analysis: accuracy of $18 \mathrm{FDG}$ PET-CT for distant metastasis staging in lung cancer patients. Surg Oncol. 2013;22(3):151-5.

12. Brady MJ, Thomas J, Wong TZ, Franklin KM, Ho LM, Paulson EK. Adrenal nodules at FDG PET/CT in patients known to have or suspected of having lung cancer: a proposal for an efficient diagnostic algorithm. Radiology. 2009;250(6):523-30.

13. Yi CA, Shin KM, Lee KS, Kim BT, Kim H, Kwon OJ, et al. Non-small cell lung cancer staging: efficacy comparison of integrated PET/CT versus 3.0-T wholebody MR imaging. Radiology. 2008;248(5):632-42.

14. Sasaki R, Komaki R, Macapinlac H, Erasmus J, Allen $\mathrm{P}$, Forster K, et al. [18F] fluorodeoxyglucose uptake by positron emission tomography predicts outcome of nonsmall-cell lung cancer. J Clin Oncol. 2005;23(1):113643.

15. Downey RJ, Akhurst T, Gonen M, Park B, Rusch V. Fluorine-18 fluorodeoxyglucose positron emission tomographic maximal standardized uptake value predicts survival independent of clinical but not pathologic TNM staging of resected non-small cell lung cancer. J Thorac Cardiovasc Surg. 2007;133(4):1419-27.

16. Kwon W, Howard BA, Herndon JE, Patz EF Jr. FDG uptake on positron emission tomography correlates with survival and time to recurrence in patients with stage I non-small-cell lung cancer. J Thorac Oncol. 2015;10(2):897-902.

17. Agarwal M, Brahmanday G, Bajaj SK, Ravikrishnan $\mathrm{KP}$, Wong CY. Revisiting the prognostic value of preoperative 18F-fluoro-2-deoxyglucose (18F-FDG) positron emission tomography (PET) in early-stage (I and II) non-small cell lung cancers (NSCLC). Eur J Nucl Med Mol Imaging. 2010;37(3):691-8.

18. Hoang JK, Hoagland LF, Coleman RE, Coan AD, Herndon JE 2nd, Patz EF Jr. Prognostic value of fluorine-18 fluorodeoxyglucose positron emission tomography imaging in patients with advancedstage non-small-cell lung carcinoma. J Clin Oncol. 2008;26(6):1459-64.

19. Detterbeck FC, Boffa DJ, Tanoue LT. The new lung cancer staging system. Chest. 2009;136(1):260-71.

20. National Comprehensive Cancer Network. Non-small cell lung cancer (version 3. 2014). http://www.nccn.org/ professionals/physician_gls/pdf/nscl.pdf.

21. FDG PET-CT in Non-small Cell Lung Cancer: Relationship between Primary Tumor FDG Uptake and Extensional or Metastatic Potential. Zhu, Shou-
Hui; Zhang, Yong; Yu, Yong-Hua; Fu, Zheng; Kong, Lei; Han, Da-Li; Fu, Lei; Yu, Jin-Ming; Li, Jia; Asian Pacific J Cancer Prev 14 (5), 2925-2929.

22. Li M, Liu N, Hu M, et al. Relationship between primary tumor fluorodeoxyglucose uptake and nodal or distant metastases at presentation in T1 stage non-small cell lung cancer. Lung Cancer 2009;63(5):383-6.

\section{Source of Support: Nil; Conflict of Interest: None}

Submitted: 31-07-2018; Accepted: 19-08-2018; Published online: 31-08-2018 